\section{Perspectivas neurocientíficas para uma teoria do trauma: revisão crítica dos modelos integrativos entre a biologia e a cultura}

\author{
Neuroscientific perspectives for a theory of \\ trauma: a critical review of integrative models of \\ biology and culture
}

\section{Perspectivas neurocientíficas para una teoría del trauma: revisión crítica de los modelos integradores entre la biología y la cultura}

Ramon Reis 1,2

Francisco Ortega 3,4

\section{Resumo}

Durante o último quarto do século $X X$, a psicopatologia codificou um arco diversificado de fenômenos sociais sob a rubrica do traumatismo, notabilizando o estudo do trauma psicológico como área autônoma e progressivamente informada pelas pesquisas culturais e neurobiológicas. Nesse cenário, presenciamos a emergência do paradigma biocultural, perspectiva epistemológica que procura elucidar as trajetórias interativas pelas quais cultura e biologia consolidam, entre si, os seus efeitos recíprocos. Este artigo abordará as interseções entre o campo dos psicotraumatismo e as neurociências, tomando, como eixos de análise, a expansão da categoria do transtorno de estresse pós-traumático (TEPT), os pressupostos epistemológicos das pesquisas neurocomportamentais do estresse e do medo, e as limitações da tese da bidirecionalidade, preconizada pelas neurodisciplinas culturais contemporâneas. A elaboração de abordagens definitivamente integrativas pode auxiliar no desenvolvimento de modelos compreensivos capazes de conceber os saberes e as práticas ao nível da experiência humana, evitando interpretações reducionistas que submetem vivências culturais e subjetivas complexas ora aos imperativos do cérebro, ora aos códigos semiológicos do raciocínio patogênico.

Transtornos de Estresse Pós-Traumático; Trauma Psicológico; Neurociências; Cultura

\author{
Correspondência \\ R. Reis \\ Universidade do Estado do Rio de Janeiro. \\ Rua São Francisco Xavier 524, pavilhão João Lyra Filho, \\ 7o andar, blocos D e E, Rio de Janeiro, RJ 20550-900, Brasil. \\ ramonrsferreira@gmail.com \\ 1 Faculdade de Medicina, Universidade Federal do Rio de Janeiro, \\ Rio de Janeiro, Brasil. \\ 2 Universidade do Estado do Rio de Janeiro, Rio de Janeiro, \\ Brasil. \\ 3 Institució Catalana de Recerca i Estudis Avançats, Barcelona, \\ Espanya. \\ 4 Centre de Recerca en Antropologia Mèdica, Universitat Rovira $i$ \\ Virgili, Tarragona, Espanya.
}




\section{Introdução}

Desde a elaboração da terceira versão do Manual Diagnóstico e Estatístico dos Transtornos Mentais 1 (DSM-III), quando a Associação Americana de Psiquiatria (American Psychiatric Association - APA) institui formalmente a categoria nosológica do transtorno de estresse pós-traumático (TEPT), presenciamos uma profunda transformação na compreensão dos distúrbios relacionados ao psicotraumatismo e o ingresso, nesse campo, de novas disciplinas e práticas dedicadas a iluminar a sua etiologia e os seus efeitos 2,3,4. Cunhado nos estertores da campanha americana no Vietnã, a valência social do construto da APA acompanhou a expansão de movimentos organizados em torno da consolidação de direitos civis de grupos sociais específicos, como é o caso do lobby dos veteranos de guerra junto à força-tarefa do DSM-III pelo reconhecimento da profunda desassistência a que estavam sujeitos 5,6. Essa conjuntura histórico-política leva o TEPT a se tornar o idioma cultural dominante para a discussão do estresse relacionado ao trauma no mundo ocidental ${ }^{7}$. Como a biomedicina ocidental continua a expandir sua influência global, o TEPT também está definindo a forma como o estresse relacionado ao trauma é compreendido nas sociedades pós-conflito. Para Theidon ${ }^{8}$, o discurso do trauma desempenha um papel fundamental nessas sociedades e na própria configuração de concepções humanitárias do sofrimento.

Nas últimas três décadas, a amplitude de aplicação do TEPT se expandiu dramaticamente, fazendo do conceito de memória traumática o vértice dominante da investida médica sobre o fenômeno do "sofrimento social" 5,9. Tal cenário denunciou a engrenagem sociopolítica por trás da elaboração de uma verdadeira indústria do trauma destinada a delimitar mercados e a fornecer especialistas para a atuação em sociedades pós-conflito 8 . Dos sobreviventes do Holocausto aos soldados americanos regressos da Guerra do Vietnã, o processo de globalização do discurso sobre o trauma apoiou-se nas intervenções de caráter humanitário para normatizar sua narrativa, confinando o sentido dos eventos perturbadores às possibilidades léxicas da racionalidade traumática 10,11,12,13.

Assim, o conceito de trauma se tornou onipresente na organização das sociedades ocidentais contemporâneas, uma episteme fornecedora do arcabouço ético por meio do qual teóricos e clínicos passaram a prescrever a virtualidade da experiência da violência e suas vicissitudes 14,15 . O trauma seria o nosso meio atual de estabelecer uma causalidade entre um sofrimento presente e uma violência passada, a cicatriz que um evento trágico deixa em uma vítima individual ou em uma testemunha, e é igualmente a marca coletiva, em um grupo, de uma experiência histórica que pode ter ocorrido décadas, gerações ou mesmo séculos atrás 6 . Para Bistoen ${ }^{15}$, sempre que um evento repentino, inesperado e terrorífico interrompe o curso natural da vida, a linguagem do trauma é recrutada por profissionais e leigos em uma tentativa de representar o impensável: hoje se fala de experiências variadas (estupro, genocídio, escravidão, tortura, ataques terroristas ou desastres ambientais) através da mesma linguagem, tanto clínica quanto metafórica do trauma: um significante para uma pluralidade de males representados 6 . A noção de trauma foi dilatada, portanto, para cobrir uma vasta gama de situações extremas e respostas individuais e coletivas diversas 14 .

Muito embora o arranjo contemporâneo na história das disciplinas autorize algum nível de sobreposição entre o conceito de estresse traumático e a categoria nosográfica do TEPT, reconhecemos, entretanto, que a sinonímia dessas noções conexas revela uma imprecisão epistemológica nefasta para o campo do psicotraumatismo, sobretudo pelo repertório ético e tecnológico que suscita. Tal foi o debate que ampliou o escopo do trauma para além dos limites semiológicos da categoria psicopatológica, viabilizando abordagens extensivas nos limiares da psiquiatria 16,17. Na opinião de Kirmayer et al. 14 (p. 1) "o trauma pode ser visto ao mesmo tempo como um evento sociopolítico, um processo psicofisiológico, uma experiência física e emocional, e um tema narrativo nas explicações do sofrimento individual e social". Logo, o estudo do trauma psicológico ultrapassa o estudo do TEPT, podendo este ser considerado como uma espécie de epifenômeno do evento mais primordial do estresse traumático 18 .

A propagação exponencial do campo dos estudos sobre o estresse traumático incorporou a pesquisa e o tratamento do trauma às áreas da psiquiatria, da psicologia e das neurociências, mas também às ciências sociais e comportamentais 19. Já em 1993, Wilson \& Raphael 19 (p. xxi) apontavam: "Para estabelecer alguma perspectiva sobre a taxa de crescimento do campo, basta reconhecer que há uma década não havia livros de referência sobre síndromes de estresse traumático, poucas medidas psicológicas padronizadas do transtorno, pouco conhecimento sobre a base biológica dos comportamentos associados a TEPT 
e uma compreensão limitada de abordagens terapêuticas eficazes. Hoje, em contraste, existem mais de 40 livros sobre trauma e vitimização, um Journal of Traumatic Stress e centenas de artigos científicos nas principais revistas profissionais".

Mais recentemente, a retórica do trauma vem sendo atravessada por referenciais éticos e teóricos resultantes do tensionamento provocado pelo ingresso de novas disciplinas na disputa pelo debate da traumatização 20,21,22,23. Essas iniciativas conjuntas repercutiram na elaboração de tratados transdisciplinares, orientados para abordagens integrativas 14,22,24, e no deslocamento epistemológico do conceito de trauma - antes monopólio discursivo estrito da psiquiatria americana 25. O trauma complexo, o trauma histórico, o trauma de massa e, mais contemporaneamente, a noção de ruptura são variantes modernas que atestam a complexificação, no seio desse debate, da acomodação de novos paradigmas associados às possibilidades da traumatização coletiva, secundária e, mesmo, transgeracional de indivíduos acometidos 26,27,28,29,30,31. Nos interessa, neste artigo, refletir acerca da pertinência epistemológica desses modelos e apontar para a relevância ética que os engendra.

\section{O neurocentrismo e as marcações biológicas do trauma}

Curiosamente, a globalização do TEPT ocorre em concomitância cronológica com a ascensão de um outro discurso, que se tornou objeto de especial atenção no fim do século XX: o neurocentrismo ${ }^{32}$. No imaginário social, a crescente percepção da autonomia cerebral em possuir propriedades e responder a ações que, anteriormente, estariam exclusivamente resguardadas ao domínio do self e da consciência converteu o órgão em um verdadeiro ator social, avivando uma personagem que ficaria amplamente conhecida como o "sujeito cerebral" 32,33,34,35. A explosão do neurocentrismo 36,37 reconduziu o campo dos estudos sobre o estresse traumático até uma arena inteiramente nova; desde a "década do cérebro" dos anos 1990, transformações intelectuais, tecnológicas, políticas e sociais estabeleceram um novo protagonismo discursivo nas ciências naturais 38 , e pesquisadores de outros campos passaram a investigar aspectos de um fenômeno que tem sido denominado, segundo as expressões "virada neural", "neurovirada" ou "virada neurocientífica" 32.

As condições para a colonização das neurociências pela episteme traumática foram oferecidas pelos avanços tecnológicos que possibilitaram investigações exitosas em discriminar os mecanismos biológicos subjacentes aos modelos animais de condicionamento do medo 4,14,39. Em 1992, Foa et al. 40 argumentaram que a semelhança entre os sintomas de indivíduos diagnosticados com TEPT e de animais submetidos a eventos aversivos imprevisíveis e incontroláveis, mais que indicar fatores etiológicos comuns, consolidaria um modelo propriamente animal daquele transtorno. Esse cenário contribuiu para o rearranjo que destacou o construto TEPT das demais síndromes de estresse póstraumático - como o transtorno de adaptação ou a psicose reativa breve - e liberou o caminho para o vínculo que atualmente se observa entre a psicotraumatologia e as disciplinas neurocientíficas. A partir de então, a compreensão das repercussões biológicas da violência reconheceria os seus correlatos cerebrais por meio de alterações na fisiologia da excitação do sistema nervoso central (SNC), do sistema nervoso autônomo (SNA) e de vários efeitos de mecanismos neuroendócrinos 41,42,43,44.

Para a biologia evolutiva, a aprendizagem e a extinção do medo, assim como os comportamentos de evitação, correspondem a mecanismos de resposta indicativos da história evolutiva humana, sendo partes de um sistema adaptativo cuja finalidade reside no manejo da periculosidade do ambiente. Isto é: lidar com a ameaça do perigo e as consequências de uma violência imaginada em sua dimensão de trivialidade, como fato corriqueiro e condição inescapável da existência. O paradigma epistemológico que orienta essa perspectiva da violência aposta em uma inversão da racionalidade que permitiu a Lifton 45 a própria conjuração da categoria nosográfica do TEPT, uma vez que, no interior de seu território, o trauma era reputado a "uma parte esperada de nosso ambiente de adaptação evolutiva" 14 (p. 12). Adicionalmente, a mesma suposição evolucionária justificou o uso de modelos animais para estudar sistemas que têm seus análogos no cérebro humano. Sobre o tema, Yehuda \& LeDoux 46 (p. 19) descrevem: "A ligação teórica entre a exposição ao estresse extremo e o desenvolvimento de TEPT forneceu a justificativa para as primeiras hipóteses de que as alterações biológicas relacionadas ao TEPT seriam semelhantes em direção às observadas agudamente em animais expostos a estressores". 
Porém, se a violência é um tipo de experiência que acompanha a humanidade desde os seus primórdios - e se é indiscutível que o estresse traumático produza transformações vindouras no próprio funcionamento do aparato cerebral -, deveríamos esperar encontrar os seus traços no design dos nossos cérebros e corpos, tanto quanto já os localizamos na trama das nossas sociedades 14. Esse é o princípio fundamental que solidariza a biologia evolucionária e a neuropsicologia, e que organiza toda a cadeia de desenvolvimentos teórico-clínico subsequentes.

Deduzida pela primeira vez por Kolb 47 a partir da analogia entre os sintomas de medo condicionado e hiperatividade em animais submetidos a choque incontrolável 48,49 e os sintomas fisiológicos e comportamentais de veteranos de combate diagnosticados com formas crônicas de TEPT, talvez essa seja, ainda, a justificativa mais bem articulada para uma hipótese neuropsicológica do TEPT 50. A partir da metáfora da estimulação emocional excessiva, Kolb 47 ambicionou delinear uma teoria compreensiva aos sinais e sintomas pós-traumáticos, cujo princípio de alteração funcional no processamento cortical neuronal e sináptico pretendia explicar os efeitos da estimulação aversiva sobre as memórias intensas. Posteriormente, muitos modelos neuropsicológicos e neurobiológicos do estresse traumático ocuparam os veículos acadêmicos de difusão, propondo a suplementação da tese pioneira de Kolb 18,51,52,53,54. Uma das reformulações da perspectiva de Kolb interpretou o TEPT como um distúrbio psicológico resultante de intensas estimulações neurais que conduziriam o aparato cerebral a desenvolver uma sensibilidade aumentada no âmbito do sistema límbico 50 . Tal fenômeno de hiper-sensibilidade neurológica 55 permitiu dedicar ao TEPT o rótulo de uma fisioneurose clássica, em que transformações neuronais anatômicas e fisiológicas serviriam de base para uma consecutiva excitabilidade neuronal extraordinária. Consistente com essa perspectiva, van der Kolk 54 vê o TEPT como uma inabilidade patológica para a modulação da excitação.

\section{Desafios para uma teoria neurocientífica do trauma}

A pesquisa neurocientífica contemporânea vem se dedicando à tentativa de explicar os substratos neurobiológicos para o TEPT, no intuito de ilustrar os seus principais fatores de risco e vulnerabilidade 7. Quando os estudos de prevalência epidemiológica demonstraram que apenas uma minoria dos indivíduos expostos a ocorrências potencialmente traumáticas desenvolve efetivamente a síndrome psiquiátrica 13 , eclodiu, no campo, uma hipótese alternativa: o TEPT seria, segundo essa concepção, uma falha dos mecanismos envolvidos na recuperação e restituição da homeostase fisiológica, possivelmente em consequência de disposições individuais prévias 46 (p. 19); portanto, "o TEPT é melhor descrito como uma condição em que o processo de recuperação do trauma é interrompido". Para van der Kolk 54, no TEPT, o equilíbrio crítico entre a amígdala e o córtex pré-frontal medial (mPFC) muda radicalmente, o que torna muito mais difícil controlar emoções e impulsos. Estudos de neuroimagem com seres humanos em estados altamente emocionais "revelam que o intenso medo, a tristeza e a raiva aumentam a ativação de regiões cerebrais subcorticais envolvidas em emoções e reduzem significativamente a atividade em várias áreas do lobo frontal, particularmente o mPFC” 54 (p. 136). Quando isso ocorre, desativam-se as capacidades inibidoras do lobo frontal, e as pessoas "deixam de lado os sentidos" 54 (p. 136).

O primeiro desafio imposto a uma teoria neurocientífica do trauma humano reside no próprio método dedutivo dos materiais coletados. Em sendo o TEPT uma síndrome clínica expressa por resposta de medo inextinguível, os achados de neuroimagem que atestam respostas exageradas da amígdala são capazes tão somente de recapitular, mas não explicar a natureza do distúrbio cerebral no TEPT 46. A distinção entre a resposta normal ao medo e a condição patológica figurada pela mesma emoção torna difícil determinar se uma mudança biológica observada é, efetivamente, um aspecto da fisiologia da doença 46. Portanto, afirmar a patogênese no ponto de convergência entre exposição ao estresse traumático e alterações biológicas é uma operação ainda interpretativa e algo enigmática, pois a causalidade inferida da relação entre o dado de neuroimagem e a resposta fisiológica ou funcional correspondente não constitui prova conclusiva de um determinado fenômeno, mas simplesmente uma operação atributiva intrínseca ao método neurocientífico ${ }^{32}$. Além disso, os modelos do estresse animal e do condicionamento do medo apreendem uma parcela significativamente restrita da experiência psicológica humana do trauma 14. Uma vez que a competência cultural é uma con- 
quista predominantemente humana, parece improvável que os modelos de cultura da neurociência comportamental possam informar as investigações da neurociência humana sobre a cultura 56.

Assim como ocorre com as descobertas do estresse, outra limitação do modelo de condicionamento do medo regular - e sua ênfase nas interações entre amígdala e o mPFC - é que ele não explica a razão pela qual apenas algumas pessoas expostas ao medo desenvolvem síndromes psicopatológicas 46. Muito embora o TEPT seja uma condição relativamente rara 57 , os sintomas dessa síndrome pós-traumática estariam presentes em quase todas as pessoas nos dias consecutivos à exposição ao trauma 58; tal achado endossa a posição de que as alterações indicativas do estresse simbolizariam o reflexo de uma resposta fisiológica universal neurobiologicamente determinada, reaquecendo a antiga contenda acerca de uma possível validade transcultural dos distúrbios traumáticos 22. Já a dificuldade em examinar o funcionamento cerebral em contextos culturalmente significativos é apenas a expressão de mais um capítulo à parte da controversa aplicação dos modelos do estresse e do condicionamento do medo à elaboração de teorias do trauma na pesquisa neurocientífica.

Além disso, até recentemente, os pesquisadores não tinham tecnologia para estudar essas questões em humanos 56. Mesmo as grandes transformações no escopo de dados e técnicas agora disponíveis para a compreensão da estrutura e da função do genoma humano, reputadas à biologia molecular ou o florescimento, nas últimas três décadas, do campo da neuroimagem humana -, necessitam de tempo para apresentar descobertas contundentes acerca da constituição mútua entre genes, cérebro, mente e cultura 56. Por outro lado, a falta de conscientização, na comunidade acadêmica, acerca dos vieses intrínsecos à produção científica em populações estudadas sob a alcunha das etiquetas "neuro" e "psi", vem estimulando que um número crescente de neurocientistas a documentar a interferência do pesquisador sobre a construção das teorias e sobre os desenhos metodológicos de experimentos futuros 56,59. Se, no campo da psicologia, 95\% das amostras psicológicas vêm de países com apenas $12 \%$ da população mundial 59, "no campo da neuroimagem humana, 90\% dos estudos revisados por pares vêm de países ocidentais" 56 (p. 289).

Já que a neurobiologia do trauma pode resultar em certas diferenças transculturais na sintomatologia, podemos conjecturar que será um desafio para os modelos neurocientíficos especializados apreender as múltiplas dimensões ontológicas da traumatização, mas, igualmente, a existência mesma de biologias locais de trauma 22 .

\section{Experiências bioculturais: o modelo da neurociência cultural}

A presumida isonomia entre as respostas humanas e animais à ameaça ou a experiências de dor e lesão é a premissa fundamental a partir da qual se ramifica a arquitetura neurobiológica que pretende inferir o trauma humano dos modelos do estresse animal e do condicionamento do medo; esse sistema conceitual de equivalências e comunicações, detendo o trunfo de produzir uma teoria "natural" do traumatismo, não deixa interdita, no entanto, as vias de acesso às dimensões culturais da causalidade patogênica. Dissimulada sob a analogia das experiências traumáticas humana e animal, a hipótese da cooperação entre suscetibilidade biológica e evento traumático concede ao TEPT uma formatação etiológica peculiar, porquanto unifica causa social reconhecível e perfil biopsicológico singular 7 . Por essa característica ontológica da formulação dessa entidade, temos, concomitantemente, a única condição psiquiátrica de etiologia perfeitamente identificável, e, por outro lado, a probabilidade que esse transtorno derive de causas sociais.

Essa condição de possibilidade delineará as abordagens integrativas do fenômeno traumático no interior do campo neurocientífico 3,22 . Seja quando, pelas manifestações sintomatológicas, a pesquisa volta o seu olhar para o passado, seja quando as considerações antropológicas autorizam a visada para as expressões idiomáticas do sofrimento 7,22, está em jogo o desenvolvimento de uma estrutura conceitual pluralista indispensável à criação de abordagens culturalmente compreensivas. As descobertas sobre como as diferenças neuroanatômicas refletem influências culturais ou em que medida contextos culturais diversos fabricam estruturas cerebrais sistematicamente distintas são enunciações deriváveis da afirmação de uma relação factível entre os fatores culturais e o funcionamento neurobiológico $21 . \mathrm{Na}$ interseção entre os estudos neurobiológicos e sociais do trauma, um certo otimismo vem sendo depositado em abordagens capazes de elaborar modelos sensíveis a contextos 
culturais familiares à experiência humana 14. Tais são os exemplos da neuropsicologia cognitiva e da neurociência cultural, que procuram inferir como os valores e as normas de sistemas de significados compartilhados, proporcionados por um determinado cenário cultural, moldam e são moldados por processos biológicos e psicológicos 21.

Circunscrito no escopo da teoria da herança dupla, o modelo de interação gene-ambiente objetiva explicar como fatores genéticos influenciam os resultados psicológicos dos indivíduos - não por ingerência direta, mas pela moderação que os dados ambientais exercem sobre a sua potencialidade determinística. A mesma prerrogativa fez deslizar a relevância da noção de risco genético para a compreensão mais acurada da suscetibilidade à influência ambiental, donde se prevê que certos genes estejam associados com o grau de sensibilidade a determinados aspectos dos estímulos ambientais. Apoiada sobre essa ideia da suscetibilidade diferencial, o modelo de interação gene-cultura pressupõe que influências genéticas moldem predisposições comportamentais e psicológicas, assim como influências culturais são capazes de moldar a manifestação social dessas predisposições, sob a forma de comportamento ou a manifestação individual delas, por meio de resultados psicológicos. Existiria, portanto, uma base genética para a suscetibilidade à entrada do ambiente que organizaria, em maior ou menor grau, os comportamentos específicos expressos em um enquadre cultural. Logo, de uma perspectiva neurocientífica, "o estudo da cultura forneceria informações valiosas sobre as maneiras pelas quais certas estruturas neurais podem servir a funções semelhantes em todas as culturas, ao mesmo tempo que são maleáveis em resposta a contribuições culturais” 21 (p. 506).

Intencionando equacionar a lacuna que historicamente estratificou os estudos da cultura e da biologia (respectivamente às ciências sociais e naturais), a neurociência cultural amadureceu como um campo emergente e interdisciplinar, cuja proposta consiste em examinar a influência bidirecional da cultura e dos genes no cérebro e no comportamento 32,56. Pouco a pouco, a interação entre o holismo etnográfico da psicologia social e o reducionismo biológico das neurociências pareceu menos excêntrica, e a combinação de teorias e métodos tão heterogeneamente dispostos no espectro científico permitiu o estudo das implicações dos valores, práticas e crenças culturais sobre a função cerebral, mas também de como o cérebro humano origina as próprias capacidades culturais 60,61.

A cultura é um sistema de mutualidades dinâmicas entre indivíduos e seus ambientes, incluindo processos biológicos e psicológicos que facilitam na adaptação e interação social 62 . Apesar da rica motivação teórica para estudar as interações cultura-biologia dentro do cérebro humano, "demonstrações empíricas precisas e modelos teóricos de relação bidirecional entre mecanismos culturais e biológicos permaneceram amplamente elusivos" 56 (p. 288). A perspectiva biocultural propõe reduzir essa lacuna de conhecimento por intermédio da elucidação das vias interativas pelas quais operam cultura e biologia. Uma maior compreensão das influências culturais e genéticas sobre a função cerebral pode amplificar o nosso conhecimento sobre os processos de traumatização, demonstrando não somente de que forma a transcrição genética denuncia a vulnerabilidade biológica pela via dos estressores sociais, mas também como o significado cultural atribuído a um evento traumático pode desempenhar um papel significativo no desenvolvimento e na severidade de uma sequela psicológica 22.

$\mathrm{Na}$ medida em que o comportamento humano resulta da atividade neural, a variação cultural no comportamento provavelmente emerge da variação cultural nos mecanismos neurais subjacentes a esses comportamentos, o que ratifica a pletora de evidências da psicologia cultural demonstrativas da influência da cultura sobre os processos psicológicos e o comportamento 56. A diversidade cultural e a variabilidade biológica sugerem a existência de uma interação de processos culturais e mecanismos biológicos para criar a heterogeneidade subsumida sob o rótulo de TEPT e, por extensão, também a outras condições pós-traumáticas correlatas. Adicionalmente, as variações culturais nos mecanismos neurais provavelmente existam mesmo na ausência de variação cultural ao nível genético ou comportamental. Nesse sentido, a neurociência seria particularmente útil para determinar quando duas operações mentais aparentemente distintas são responsáveis por processos subjacentes e, inversamente, quando duas operações aparentemente semelhantes derivam de processos neurais bastante diferentes 61 .

Ao usar a estrutura da neurociência cultural para identificar e investigar fenômenos candidatos usando a abordagem de vários níveis de análise, aumentaremos nossas chances de compreender como as forças socioculturais e biológicas interagem e moldam umas às outras, bem como encontrar maneiras potenciais de direcionar esse conhecimento para questões oportunas na saúde da população 56. 
Uma vez que a abrangência de achados biológicos reconhece a relação entre o TEPT e o eixo hipotalâmico-pituitário-adrenal (HPA), tornando assim improvável a existência de um perfil unívoco para essa condição/psicopatologia, provavelmente existam também diferentes caminhos produzidos por meio de variações nos ambientes de desenvolvimento, no contexto pré-trauma, nos tipos e significados de experiências traumáticas e circunstâncias após exposições traumáticas 22. Portanto, a interpretação do fenômeno traumático a partir de uma perspectiva biocultural pode facilitar o desenvolvimento de modelos integrativos convenientes a uma compreensão mais acurada do sofrimento associado às múltiplas condições pós-traumáticas e aos seus meios de intervenção mais apropriados.

O dissenso de matrizes explicativas da diversidade cultural dos mecanismos neurais - para uns, resultante de polimorfismos genéticos 56; para outros, sobrevinda essencialmente de um contexto social determinante para a resposta biológica na psicopatologia - não recusa a admitir, entretanto, um postulado comum: tratar a cultura e a biologia como processos independentes produzirá interpretações incompletas e, possivelmente, equivocadas 22 . Um modelo interativo que examine como a biologia e a cultura coproduzem a experiência de vida, incluindo o TEPT, seria fundamental para elucidar os fatores de risco e recuperação em condições pós-traumáticas.

\section{Limitações dos modelos bidirecionais em neurociências}

Que tipo de seres pensamos que somos? "Somos pessoas psicológicas, habitadas por uma psique profunda e interior moldada por experiências, símbolos e signos, significado e cultura?". "Nossa própria natureza humana é moldada pela estrutura e funções de nossos cérebros?” 63 (p. 1). Tentando responder a esses questionamentos, as novas ciências do cérebro procuraram sustentar o alinhamento com uma forma de racionalidade que representa a corporeidade em constante intercâmbio com seu meio, em que o biológico e o social não são dimensões distintas, mas sim entrelaçadas 63. O otimismo que acompanhou a formação das neurodisciplinas da cultura, entretanto, não se traduziu na elaboração de modelos definitivamente representativos da experiência biopsicossocial humana 64,65 . Isso porque a corporificação neuroanatômica de conceitos e significados culturais ou a afirmação de diferenças neurais subjacentes às diferenças psicológicas, embora constituam preceitos axiomáticos dessas abordagens, não são ainda empiricamente verificáveis e tampouco suficientes para explicar a fenomenologia da aprendizagem, da memória, ou mesmo do trauma 32,66 .

O surgimento de uma perspectiva neuromolecular do cérebro, por meio da qual sua estrutura e funcionamento tornaram-se compreensíveis enquanto processos materiais de interação entre moléculas, foi fundamental para a consolidação da crença de que podemos ver a mente, a cultura ou quaisquer produtos humanos diretamente no cérebro vivo 63,67. Não só as paixões, os desejos, as crenças, as emoções e os comportamentos passaram a ser concebidos em termos das propriedades biofísicas, químicas e elétricas de suas partes constituintes, mas a própria conduta no mundo cotidiano poderia ser transcrita pelos correlatos neurais capturados no imageamento cerebral 32,63. Está longe de ser recente a crítica de que a linguagem, a história, a sociedade e a cultura, em suma, as dimensões-chave da humanidade, sejam dificilmente concebíveis pela simples ação anódina de cérebros, e não de indivíduos complexos 67 . No entanto, permanece verdadeiro que, se o cérebro humano evolui pela e para a estrita função da sociabilidade, isto é, para a capacidade de viver em grupos e para responder aos estados mentais dos outros, é porque o modelo ético que subjaz a sua compreensão permanece estabelecido sobre a unidirecionalidade causal 63. Pois se a mente humana, e seus múltiplos produtos linguísticos, sociais e culturais, é concebida apartada das estruturas e composição do mundo material, é porque se argumenta, mais ou menos explicitamente, que há uma espécie de complementaridade essencial das dimensões biogenética e sociocultural da existência humana 68 .

A tese da complementaridade entende os seres humanos como constituídos simultaneamente enquanto organismos dentro de sistemas de relações ecológicas e enquanto pessoas com sistemas de relações sociais 67 . A tarefa crítica seria, então, compreender a interação recíproca entre os dois tipos de sistema, social e ecológico 68. Uma vez que todo organismo é uma entidade discreta e limitada, ou seja, o representante de uma população de seres aparentados se relacionando com outros organismos, as linhas de contato que prescrevem as suas interações não seriam suficientes para transformar a estrutura de sua natureza básica. Nesse modelo, organismos e pessoas são concebidos como com- 
ponentes separados no ser humano - ao primeiro, correspondendo a dimensão populacional; ao segundo, a dimensão relacional 68. Porém, se todo organismo "não é tanto uma entidade discreta mas um ânodo em um campo de relações" 68 (p. 3), então, temos que pensar em uma nova racionalidade biológica. A combinação de pensamento "relacional" em antropologia, pensamento "ecológico" em psicologia e pensamento de "sistemas de desenvolvimento" em biologia, realizada por Ingold 68, produziu uma síntese cuja concepção ontológica não estaria mais sustentada em uma entidade composta por partes separáveis embora complementares, como corpo, mente e cultura, mas sim como um "locus singular de crescimento criativo dentro de um campo de relações em contínuo desdobramento" 68 (p. 4). A vida orgânica, nessa perspectiva, não é tanto a realização de formas pré-especificadas, mas o próprio processo em que as formas são geradas e estabilizadas.

Portanto, a que corresponde esse agregado constituído por organismo mais ambiente que costuma perpassar a definição antropológica de um sujeito social imerso nas trocas culturais, mas também na fisicalidade do universo material? No pensamento de Ingold 68, uma perspectiva antiecológica da mutualidade entre organismo e ambiente requer um organismo genotipicamente especificado e, por complemento, um ambiente reprisador de um conjunto de restrições físicas que lhe serão incutidas. Obviamente, a ecologia convencional representa organismo e ambiente em planos sobrepostos, ambos os quais possuindo integridade exclusiva e independente da reciprocidade que porventura venham a estabelecer 67 . Em contrapartida, uma abordagem ecológica deve fornecer o elo entre a vida biológica do organismo em seu ambiente e a vida cultural da mente na sociedade, e, portanto, o agregado de organismo mais ambiente deve denotar não um composto de duas coisas, mas uma totalidade indivisível. À matriz interpretativa do sistema de desenvolvimento representado por essa totalidade, Ingold 68 denominou "ecologia vital".

Reiteramos que o projeto neurocientífico da bidirecionalidade permanece vigorosamente confinado ao dualismo e ao problema filosófico que originou as doutrinas reducionistas modernas, sejam elas de tradição materialista, sejam de matriz socioconstrutivista 67 . Mesmo não apregoando explicitamente, as suas disciplinas tampouco abandonam a formulação axiomática que institui a hipótese da complementaridade: a ideia de que as coisas próprias ao corpo são incognoscíveis à mente, e que as coisas dadas a essa estão alienadas do conhecimento pelos processos da corporeidade. Além disso, mesmo não sendo categórica em representar a mente como apenas uma das numerosas propriedades emergentes do cérebro 63 , a tese da bidirecionalidade dissimula, por trás de seu suposto determinismo recíproco ${ }^{64}$, uma marcante assimetria causal que reafirma a primazia ontológica desse sobre as dimensões da mente e da cultura ${ }^{32}$. Representando grupos humanos como comunidades de cérebros - e a diversidade cultural como neurodiversidade -, esse processo de neurologização secundariza a posição da cultura com o apelo ao aplainamento dos conceitos e significados culturais. Exemplos desse fenômeno são a utilização extensa da neuroimagem como artefato investigativo e elemento essencial para a interpretação e a elaboração de desenhos experimentais 69 e as expectativas de correção farmacológica de distúrbios neurobiológicos oriundos de experiências traumáticas 54.

Portanto, a confiança que envolveu os modelos bioculturais no universo neurocientífico, consubstanciada por promessas exuberantes 56,70, ainda não superou suficientemente as dualidades cérebro-pessoa e cultura-indivíduo, pelas quais a filosofia da ciência implementou o reducionismo materialista característico à racionalidade ocidental 71. Sentenças como "o comportamento humano é resultado da atividade neural" 56 (p. 290) ou "o cérebro deu origem à mente" 69 (p. 646), mais do que tipificar a ambição do campo em celebrar a descoberta de uma panaceia para alguns dos mistérios imemoriais da humanidade, simbolizam a existência de uma hierarquia epistêmica implícita que embaraça o aceno das neurodisciplinas da cultura à sinergia e à bidirecionalidade 32 . Com efeito, a etiqueta "cultural" nas neurociências não traduz a predileção das suas disciplinas pelos dados neurobiológicos.

Ademais, a concepção de mente e da cultura enquanto precipitados de operações cerebrais elementares contribui para uma compreensão homogeneizante de processos sociais e culturais diversos 32 . O próprio proceder neurocientífico, fundamentado na inferência de hipóteses pela conjugação de resultados correlacionais e argumentações causais, pode reforçar definições apriorísticas, naturalizando estereótipos culturais no laboratório 72 . A utilização de categorias unívocas como "cultura ocidental" e "cultura leste-asiática" nos desenhos experimentais de pesquisas em neurociência cultural e neuroantropologia retratam esse processo de simplificação 69. Da mesma maneira, se a vantagem de desvelar a "inscrição cerebral" de uma possível afiliação cultural, mesmo na ausência de comportamento obser- 
vável, reitera o princípio de que normas, crenças e significados se corporificam nos indivíduos de um dado grupo, por outro, reserva, ao nível neural, a posse de uma verdade sobre os humanos como seres culturais que, paradoxalmente, não poderia ser reconhecida pelo estudo das próprias práticas sociais e culturais 32 . Ainda, uma vez que o mapeamento neural pode sinalizar regiões e estruturas cerebrais recrutadas mas não os significados envolvidos na realização de uma tarefa, dificilmente o achado de neuroimagem será definitivo para indicar de que maneira a experiência cultural é capaz de modular padrões preexistentes da atividade neural. Para Vidal \& Ortega 32 , a questão central é se, finalmente, as neurodisciplinas atendem à sua finalidade essencial de lançar novas luzes sobre a cultura.

\section{Conclusão}

As últimas três décadas testemunharam uma profunda expansão no uso das neurociências para estudar processos sociais e cognitivos complexos, bem como da psicologia cultural para compreender a diversidade humana 61. Conforme o campo dos estudos sobre o estresse traumático procurou se informar cada vez mais a partir do raio de ação das pesquisas culturais e neurobiológicas, presenciamos um fenômeno síncrono que teve, por consequência, a exportação da racionalidade do discurso do traumatismo para outras disciplinas e saberes e, concomitantemente, o reforço do dispositivo neurocientífico enquanto método essencial de busca pela verdade.

Atualmente, o TEPT é considerado uma categoria psicopatológica hegemônica, concentrando, em sua órbita, múltiplas linhas de financiamento e uma profusão de pesquisas interessadas em representar o fenômeno do trauma a partir do modelo descritivo que, desde a revolução do DSM-III, expurgou a nosografia oficial americana de sua matriz psicodinâmica 73 . O TEPT figura como um ponto de confluência entre diversas áreas de conhecimento - locus da interseção entre as neurociências, a psiquiatria e a psicotraumatologia, cujo predomínio indica a solidariedade que veicula episteme traumática e neurodisciplinas 46 . A produção científica atesta a crescente utilização do instrumental tecnológico neurocientífico no estudo e na compreensão dos distúrbios relacionados ao psicotraumatismo 18,51,54; todavia, diferentemente do que ocorre em outros campos científicos, em que as neurociências notavelmente impuseram o seu método 54 , seria mais preciso afirmar que houve um intercâmbio, com o trânsito mútuo do modelo neurocientífico, expandindo-se sobre o universo da traumatização, enquanto o discurso do trauma incutiu, naquele, o seu preceito de irreversibilidade dos processos fenomênicos: dupla propagação que faz interrogar se um dos desdobramentos da neurologização da cultura seria uma espécie de "neurologização do trauma" e, por conseguinte, se esse corresponderia a mais um aspecto acessório da neurovirada 32 .

Destacamos as inconsistências da aplicação de modelos neurocomportamentais do estresse e do condicionamento do medo em animais para a compreensão da complexidade da experiência biopsicossocial humana 40. Esses modelos, fundados sobre o paradigma da violência enquanto condição evolucionária intrínseca à espécie, costumam resultar na simplificação da experiência cultural com a finalidade de preservar a pretensa isonomia dos funcionamentos cerebrais humano e animal, o que garante a utilidade e a adequação de suas evidências experimentais 14 .

Recentemente, a teoria do coconstrutivismo biocultural surgiu como um método enunciativo das trajetórias de desenvolvimento por meio das quais fatores genéticos e culturais se comunicam, mas, sobretudo, como forma de explicar a competência da plasticidade neural sobre o redirecionamento dessas trajetórias e, mesmo, de suas vicissitudes 74 . Um dos modelos conceituais representativos desse paradigma é o da neurociência cultural. Nesse modelo, a neuroimagem transcultural é utilizada para inferir a articulação bidirecional e as propriedades emergentes de processos mentais, neurais e genômicos 21 . Ames \& Fiske 61 argumentam que a abordagem integrativa da neurociência cultural, além de nos auxiliar na construção de um quadro mais completo das relações entre cultura, psicologia e biologia, pode consolidar outros benefícios; quais sejam, o aprimoramento de práticas educacionais, o desenvolvimento de uma progressiva compreensão intercultural mútua e a elaboração de cuidados em saúde mental mais eficazes para pessoas globalmente 61.

Embora frequentemente retratada como uma "disciplina do futuro" 56, ressaltamos alguns dos desafios ainda colocados para a neurociência cultural - bem como para outras neurodisciplinas destinadas a compreender como o cérebro "medeia" interações sociais e culturais e produz emoção 
e cognição 32. Dentre eles, a existência de uma hierarquia epistêmica que desautoriza que múltiplas causalidades interfiram e influenciem na interpretação dos fenômenos bioculturais; a justaposição de dados culturais e neurobiológicos que servem à homogeneização da cultura pelos métodos e projetos experimentais neurocientíficos; e a adoção de noções epistemológicas reducionistas que operam na simplificação e universalização dos conceitos e significados compartilhados próprios aos processos culturais 64,49 .

Resta saber se o monopólio do raciocínio etiopatogênico contemporâneo conquistado pelo par neurociências-trauma será capaz de facilitar o desenvolvimento de práticas sensíveis às realidades socioculturais de populações variadas ${ }^{14}$. Mesmo as abordagens integrativas do campo neurocientífico, embora encaminhem problemas dificilmente solucionáveis em perspectivas comportamentais ou medidas de autorrelato, ainda carregam uma tradição dualista das concepções do cérebro, da mente e da cultura, e analisam esses fenômenos e suas interações a partir de ênfases especializadas que compartimentam a experiência biopsicossocial humana ${ }^{70}$. A concretização do projeto biocultural depende, em algum grau, da consideração dos contextos históricos e da observância de uma conceitualização compreensiva da cultura não só na interpretação dos experimentos, mas na concepção mesma dos seus desenhos metodológicos, abordando a significação transcultural de categorias experimentais e a influência das crenças culturais sobre o projeto e o resultado das pesquisas na área 72 . A elaboração de abordagens definitivamente integrativas pode auxiliar no desenvolvimento de modelos capazes de conceber os saberes e as práticas ao nível da experiência humana, evitando, assim, representações mecânicas e abstratas que equivalem a cultura a um epifenômeno circunscrito pela atividade do córtex pré-frontal 75 . No campo do psicotraumatismo, que expandiu notavelmente a sua abrangência no século XX, esse desfecho é essencial, pois significaria que pessoas e grupos acometidos por vivências radicais estariam menos sujeitas a interpretações reducionistas que submetem experiências subjetivas e culturais complexas ora aos imperativos do cérebro, ora aos códigos semiológicos do raciocínio patogênico. Porém, especialmente, significaria corrigir a histórica exclusão da dimensão cultural sobre a racionalidade social, etiológica e clínica comuns ao repertório teórico-tecnológico geralmente recrutado em resposta à emergência do acontecimento traumático.

\section{Colaboradores}

Todos os autores colaboraram igualmente em todas as etapas da elaboração deste artigo (concepção, redação e revisão do material apresentado).

\section{Informações adicionais}

ORCID: Ramon Reis (0000-0003-0175-8676); Francisco Ortega (0000-0002-5039-9449.

\section{Referências}

1. American Psychiatric Association. Diagnostic and statistical manual of mental disorders. 3rd Ed. Washington DC: American Psychiatric Association; 1980.

2. Scott WJ. PTSD in DSM-III: a case in the politics of diagnosis and disease. Social Problems 1990; 37:294-310.

3. Konner M. Trauma, adaptation, and resilience: a cross-cultural and evolutionary perspective. In: Kirmayer LJ, Lemelson R, Barad M, editors. Understanding trauma: integrating biological, psychological and cultural perspectives. New York: Cambridge University Press; 2007; p. 300-38.

4. Cohen H, Kozlovsky N, Alona C, Matar MA Joseph Z. Animal model for PTSD: from clinical concept to translational research. Neuropharmacology 2012; 62:715-24.

5. Young A. The harmony of illusions: inventing post-traumatic stress disorder. Princeton: Princeton University Press; 1995. 
6. Fassin D, Rechtman R. The empire of trauma: an inquiry into the condition of victimhood. Princeton: Princeton University Press; 2009.

7. Mochimi Y. Anthropological discourses on the globalization of posttraumatic stress disorder (PTSD) in post-conflict societies. J Psychiatr Pract 2012; 18:29-37.

8. Theison K. Intimate enemies: violence and reconciliation in Peru. Philadelphia: University of Pennsylvania Press; 2013.

9. Wilkinson I, Kleinman A. A passion for society: how we think about human suffering. Oakland: University of California Press; 2016.

10. Breslau N, Chilcoat HD, Kessler RC, Davis GC. Previous exposure to trauma and PTSD effects of subsequent trauma: results from the Detroit area survey of trauma. Am J Psychiatry 1999; 156:902-7.

11. Breslau J. Globalizing disaster trauma: psychiatry, science, and culture after the Kobe Earthquake. Ethos 2000; 28174-197.

12. Breslau N. The epidemiology of trauma, PTSD, and other posttrauma disorders. Trauma, Violence \& Abuse 2009; 10:198-210.

13. Kessler RC, Aguilar-Gaxiola S, Alonso J, Benjet C, Bromet EJ, Cardoso G, et al. Trauma and PTSD in the WHO World Mental Health Surveys. Eur J Psychotraumatol 2017; 8 Suppl 5:1353383.

14. Kirmayer L, Lemelson R, Barad M. Introduction: inscribing trauma in culture, brain, and body. In: Kirmayer LJ, Lemelson R, Barad M, editors. Understanding trauma: integrating biological, psychological and cultural perspectives. New York: Cambridge University Press; 2007. p. 1-20.

15. Bistoen G. Trauma, ethics and the political beyond the PTSD: the dislocations of the real. New York: Palgrave Macmillan; 2016.

16. Solomon Z, Dekel R, Mikulincer M. Complex trauma of war captivity: a prospective study of attachment and post-traumatic stress disorder. Psychol Med 2008; 38:1427-34.

17. Greeson J, Briggs EC, Kisiel CL, Layne CM, Ake 3rd GS, Ko SJ, et al. Complex trauma and mental health in children and adolescents placed in foster care: findings from the $\mathrm{Na}$ tional Child Traumatic Stress Network. Child Welfare 2011; 90:91-108.

18. Everly GS, Lating JM. Psychotraumatology: key papers and core concepts in post-traumatic stress. New York: Springer Science+Business Media; 1995.

19. Wilson JP, Raphael B. International handbook of traumatic stress syndromes. New York: Springer Sciencee+Business Media; 1993.

20. van der Kolk, Bessel A. The neurobiology of childhood trauma and abuse. Child Adolesc Psychiatr Clin N Am 2003; 12:293-317.

21. Kim HS, Sasaki JY. Cultural neuroscience: biology of the mind in cultural contexts. Annu Rev Psychol 2014; 65:487-514.

22. Hinton DE, Good BJ. Culture and PTSD: trauma in global and historical perspective. Philadelphia: University of Pennsylvania Press; 2016.
23. Curry A. Neuroscience starts talking. Nature 2017; 551:S81-3.

24. Marsella AJ, Johnson JL, Watson P, Gryczynski J. Ethnocultural perspectives on disaster and trauma: foundations, issues, and applications. New York: Springer Science+Business Media; 2008.

25. Behrouzan O. Ruptures and their afterlife: a cultural critique of trauma. Middle East Topics \& Arguments 2018; 11:131-44.

26. Herman JL. Trauma and recovery: the aftermath of violence - from domestic abuse to political terror. New York: Basic Books; 1992.

27. Heart MYHB. The historical trauma response among natives and its relationship with substance abuse: a Lakota illustration. J Psychoactive Drugs 2003; 35:7-13.

28. Courtois CA. Complex trauma, complex reactions: assessment and treatment. Psychotherapy: Theory, Research, Practice, Training 2004; 41:412-25.

29. Sotero M. A conceptual model of historical trauma: implications for public health practice and research. J Health Dispar Res Pract 2006; 1:93-108.

30. Schwab G. Haunting legacies: violent histories and transgenerational trauma. New York: Columbia University; 2010.

31. Goodman RD. The transgenerational trauma and resilience genogram. Couns Psychol Q 2013; 26:386-405.

32. Vidal F, Ortega F. Being brains: making the cerebral subject. New York: Fordham University Press; 2017.

33. Ortega F. O sujeito cerebral e o movimento da neurodiversidade. Mana 2008; 14:477-509.

34. Ortega F. Elementos para uma história da neuroascese. Hist Ciênc Saúde-Manguinhos 2009; 16:621-40.

35. Ehrenberg A. O sujeito cerebral. Psicol Clín 2009; 21:187-213.

36. Martín-Rodríguez JF, Cardoso-Pereira N, Bonifácio V, Barroso y Martín JM. La década del cerebro (1990-2000): algunas aportaciones. Revista Española de Neuropsicologia 2004; 6:131-70.

37. Castro FS, Landeira-Fernandez J. Notas históricas acerca do debate mente e cérebro. ComCiência 2012; (144). http://comciencia.scielo. br/scielo.php?script=sci_arttext\&pid=S1519$76542012001000009 \& \operatorname{lng}=$ pt\&nrm $=$ is.

38. Jones EG, Mendell LM. Assessing the decade of the brain. Science 1999; 284:739.

39. Siegmund A, Wotjak CT. Toward an animal model of posttraumatic stress disorder. Ann N Y Acad Sci 2006; 1071:324-34.

40. Foa EB, Zinbarg R, Rothbaum B. Uncontrollability and unpredictability in post-traumatic stress disorder: An animal model. Psychol Bull 1992; 112:218-38.

41. Kardiner A. Traumatic neuroses of war. In: Arieti S, editor. American handbook of psychiatry. New York: Basic Books; 1959. p. 245-57.

42. Eerly GS. Post-traumatic stress disorder as a disorder of arousal. Psychology \& Health 1990; 4:135-45. 
43. Bremmer JD, Vythilingam M, Vermetten E, Adil J, Khan S, Nazeer A, Afzal N, et al. Cortisol response to a cognitive stress challenge in posttraumatic stress disorder (PTSD) related to childhood abuse. Psychoneuroendocrinology 2003; 28:7337-50.

44. Bremmer JD. Does the stress damage the brain? In: Kirmayer L, Lemelson R, Barad M, editors. Understanding trauma: integrating biological, psychological and cultural perspectives. New York: Cambridge University Press; 2007. p. 118-41.

45. Lifton R. Understanding the traumatized self: imagery, symbolization and transformation. In: Wilson JP, Harel Z, Kahana B, editors. Human adaptation to extreme stress: from Holocaust to Vietnam. New York: Harper \& Row; 1988. p. 7-31.

46. Yehuda R, Ledoux J. Response variation following trauma: a translational neuroscience approach to understanding PTSD. Neuron Review 2007; 56:19-32.

47. Kolb LC. A neuropsychological hypothesis explaining posttraumatic stress disorders. American Journal of Psychiatry 1987; 144:989-95.

48. Bortoloti R, Dos Reis, Maria JD, De Rose JC. Efeitos de seis manipulações experimentais sobre a aprendizagem de uma nova resposta de fuga. Interação Psicol 2006; 10:313-9.

49. Takase LF, Nogueira MI, Baratta M, Bland ST, Watkins LR, Maier SF, et al. Inescapable shock activates serotonergic neurons in all raphe nuclei of rat. Behav Brain Res 2004; 153:233-9.

50. Horton AM. Neuropsychology of PTSD: problems, prospects, and promises. In: Everly GS, Lating JM, editors. Psychotraumatology. Boston: Springer; 1995. p. 147-58.

51. Nelson CA, Carver LJ. The effects of stress and trauma on brain and memory: a view from developmental cognitive neuroscience. Development and Psychopathology 1998; 10:793-809.

52. Gilbertson MW, Shenton ME, Ciszewski A, Kasai K, Lasko NB, Orr SP, et al. Smaller hippocampal volume predicts pathologic vulnerability to psychological trauma. Nature Neuroscience 2002; 5:1242-7.

53. Goodman M, New A, Seiver L. Trauma, genes, and the neurobiology of personality disorders. Ann N Y Acad Sci 2009; 1032:104-16.

54. van der Kolk BA. The body keeps the score: brain, mind, and body in the healing of trauma. New York: Penguin Books; 2016.

55. Eerly GS, Horton AM. Neuropsychology of posttraumatic stress disorder: a pilot study. Percept Mot Skills 1989; 68:807-10.

56. Chiao JY. Cultural neuroscience: a once and future discipline. In: Chiao JY. Cultural neuroscience: cultural influences on brain function. New York: Elsevier; 2009. p. 287-304.

57. Yehuda R. Risk and resilience in posttraumatic stress disorder. J Clin Psychiatry 2004; 65: 29-36.
58. McFarlane AC. Posttraumatic stress disorder: a model of the longitudinal course and the role of the risk factors. J Clin Psychiatry 2000; 61:15-23.

59. Arnett JJ. The neglected 95\%: why American psychology needs to become less American. American Psychologist 2008; 63:602-14.

60. Chiao JY, Ambady N. Cultural neuroscience: parsing universality and diversity across levels of analysis. In: Cohen D, Kitayama S, editors. Handbook of cultural psychology. New York: The Guilford Press; 2007. p. 237-54.

61. Ames DL, Fiske ST. Cultural neuroscience. Asian J Soc Psychol 2010; 13:72-82.

62. Wajman JR, Bertolucci PHF, Mansur LL, Gauthier S. Culture as a variable in neuroscience and clinical neuropsychology. Dement Neuropsychol 2015; 9:203-18.

63. Rose N, Abi-Rached JM. Neuro: the new brain sciences and the management of the mind. Princeton: Princeton University Press; 2013.

64. Zhou H, Cacioppo J. Culture and the brain: opportunities and obstacles. Asian J Soc Psychol 2010; 13:59-71.

65. Kitayama S, Tompson S. Envisioning the future of cultural neuroscience. Asian J Soc Psychol 2010; 13:92-101.

66. Lende DH, Downey G. The encultured brain: an introduction to neuroanthropology. Cambridge: MIT Press; 2012.

67. Fuchs T. Ecology of the brain: the phenomenology and biology of the embodied mind. Oxford: Oxford University Press; 2018.

68. Ingold $\mathrm{T}$. The perception of the environment: essays on livelihood, dwelling and skill. New York: Routledge; 2000.

69. Han S, Northoff G. Culture-sensitive neural substrates of human cognition: a transcultural neuroimaging approach. Nat Rev Neurosci 2008; 9:646-54.

70. Kitayma S, Cohen D. Handobook of cultural psychology. New York: Guilford Press; 2010.

71. Bickle J. Reducing mind to molecular pathways: explicating the reductionism implicit in current cellular and molecular neuroscience. Synthese 2006; 151:411-34.

72. Choudhury S. Culturing the adolescent brain: what can neuroscience learn from anthropology? Soc Cogn Affect Neurosci 2010; 5:159-67.

73. Russo J, Venâncio ATA. Classificando as pessoas e suas perturbações: a "revolução terminológica” do DSM III. Rev Latinoam Psicopatol Fundam 2006; 9:460-83.

74. Li S-C. Biocultural orchestration of developmental plasticity across levels: the interplay of biology and culture in shaping the mind and behavior across the life span. Psychol Bull 2003; 129:171-94.

75. Zhu Y, Zhang L, Fan J, Han S. Neural basis of cultural influence on self-representation. Neuroimage 2007 ; 34:1310-6. 


\section{Abstract}

In the last 25 years of the 20th century, psychopathology coded a diverse range of social phenomena under the heading of trauma, featuring the study of psychological trauma as an autonomous area progressively informed by cultural and neurobiological research. In this scenario, we witnessed the emergence of the biocultural paradigm, an epistemological perspective that seeks to elucidate the interactive trajectories by which culture and biology consolidate each other's effects. This article will address the intersections between the field of psychological trauma and neurosciences, based on the analytical dimensions of expansion of the category of posttraumatic stress disorder (PTSD), the epistemological premises of neurobehavioral studies of stress and fear, and the limitations of the bidirectionality hypothesis advanced by contemporary cultural neurosciences. The elaboration of definitively integrative approaches can assist the development of comprehensive models capable of conceiving knowledges and practices at the level of human experience, avoiding reductionist interpretations that submit complex cultural and subjective experiences alternatingly to the imperatives of the brain and to semiologic codes of pathogenic reasoning.

Post-Traumatic Stress Disorders; Psychological Trauma; Neurociences; Culture

\section{Resumen}

Durante el último cuarto del siglo XX, la psicopatología codificó un arco diversificado de fenómenos sociales, bajo la rúbrica del traumatismo, poniendo en relevancia el estudio del trauma psicológico, como área autónoma, y progresivamente informada por las investigaciones culturales $y$ neurobiológicas. En este escenario, presenciamos el surgimiento del paradigma biocultural, perspectiva epistemológica que procura elucidar las trayectorias interactivas por las cuales cultura $y$ biología consolidan, entre sí, sus efectos recíprocos. Este artículo abordará las intersecciones entre el campo de los psicotraumatismos y las neurociencias, tomando, como ejes de análisis, la expansión de la categoría del trastorno de estrés postraumático (TEPT), los presupuestos epistemológicos de las investigaciones neurocomportamentales del estrés $y$ del miedo, y las limitaciones de la tesis de la bidireccionalidad, preconizada por las neurodisciplinas culturales contemporáneas. La elaboración de abordajes definitivamente integradores pueden apoyar el desarrollo de modelos comprensivos, capaces de concebir los saberes y prácticas en el nivel de la experiencia humana, evitando interpretaciones reduccionistas que someten vivencias culturales y subjetivas complejas, bien sea a los imperativos del cerebro, bien sea a los códigos semiológicos del raciocinio patogénico.

Trastornos por Estrés Postraumático; Trauma Psicológico; Neurociencias; Cultura
Recebido em 21/Dez/2020

Versão final reapresentada em 08/Mai/2021

Aprovado em 21/Mai/2021 